\title{
Shrot Communication
}

[Agr. Biol. Chem., Vol. 35, No. 3, p. 445 446, 1971]

\section{Synthesis of $d l$-Phyllostine}

Sir:

In previous papers, ${ }^{11}$ we reported the isolation and structural determination of phyllostine (I), one of the new phytotoxic compounds ${ }^{2}$ isolated from the culture filtrates of phyllosticta sp. We now wish to describe the synthesis of the compound. The starting material, 2-hydroxymethyl-1,4-benzoquinone, was prepared by the oxidation of gentisyl alcohol with lead tetraacetate according to the known procedure. ${ }^{31}$ Oxidation of the benzoquinone utilizing $t$-butylhydroperoxide ${ }^{4}$ as the oxidizing agent and Triton $B$ as the base in non-aqueous solvent using absolute ethanol-dioxane gave a complex mixture because of the decomposition of the products. An attempt to oxidize the benzoquinone with $m$-chloroperbenzoic ${ }^{51}$ acid failed and the starting material was recovered. Finally, epoxidation of the benzoquinone with sodium perborate according to Read's procedure ${ }^{6)}$ was examined and was entirely successful. Optimum conditions were found as follows.

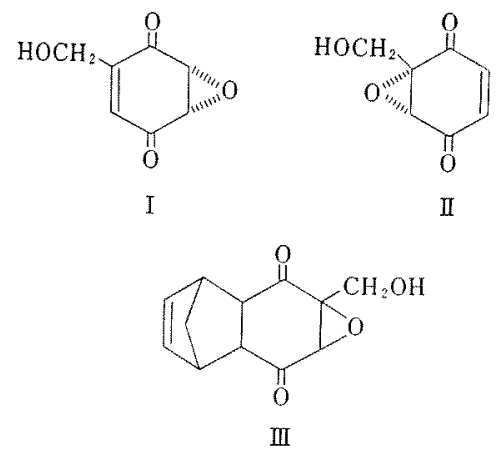

1) S. Sakamura, J. Ito and R. Sakai, Agr. Biol. Chem., 34, 153 (1970); S. Sakamura, J. Ito and R. Sakai, ibid., 35, 105 (1971).
To the solution of benzoquinone $(800 \mathrm{mg})$ in methanol was added a solution of sodium perborate $(1.320 \mathrm{~g})$ in $96 \mathrm{ml}$ of water, which had been adjusted to $\mathrm{pH} 8.5$ with acetic acid. After stirring for $10 \mathrm{~min}$, the reaction mixture was acidified to $\mathrm{pH} 5.5$ with acetic acid and extracted with ethyl acetate. The product was chromatographed on silica gel using chloroform-methanol $(95: 5 \mathrm{v} / \mathrm{v})$ as solvent. Although the purified product showed only one spot on TLC and paper chromatography in various solvent systems, the NMR spectrum indicates that the product contains the two epoxide compounds (I, II) and the minor component might be an epoxide isomer II because the signal due to a hydroxymethyl group in II appeared at $\tau$ 5.90. Therefore, the mixture was treated with cyclopentadiene to form selectively a Diels-Alder adduct III which would be removed by chromatography. The reaction product was effectively separated by column chromatography using silicic acid to give two crystalline compounds. One of the product, $\mathrm{mp} 125.2 \sim 126^{\circ} \mathrm{C}$, was assigned as III by the elemental analysis and spectroscopic data. Anal. Found: $\mathrm{C}, 65.52 ; \mathrm{H}, 5.41$. Calcd. for $\mathrm{C}_{12} \mathrm{H}_{12} \mathrm{O}_{4}$ : C, 65.44; H, 5.49\%ó. IR, $\nu_{\max }^{\mathrm{KBr}} \mathrm{cm}^{-1} 3400$, 3070, 3040, 1710, 845, NMR (in $\mathrm{CDCl}_{3}$ ) $\tau:$ 8.50 $8.70\left(\mathrm{~m} \mathrm{CH}_{2}\right), 6.67$ (2H, broads, $\left.\mathrm{C}-\stackrel{\mathrm{C}}{\mathrm{C}} \mathrm{H}-\right), 6.52$ $(2 \mathrm{H}, \mathrm{S},-\stackrel{\mathrm{C}}{\mathrm{H}} \mathrm{H}-\mathrm{CO}), 6.40\left(1 \mathrm{H}, \mathrm{S},{\stackrel{\mathrm{O}}{\mathrm{CH}_{1}}}\right), 6.03$

2) S. Sakamura, H. Niki, Y. Obata, R. Sakai and T. Matsumoto, Agr. Biol. Chem., 33, 698 (1969).

3) A. Black, Helv. Chim. Acta, 30, 1 (1947).

4) H. W. Moor, J. Org. Chim., 32, 1996 (1967).

5) V. R. Valente and J. L. Wolfhagen, ibid., 31, 2509 (1966).

6) A. Rashid and G. Read, J. Chem. Soc., (C), 1967, 1323. 


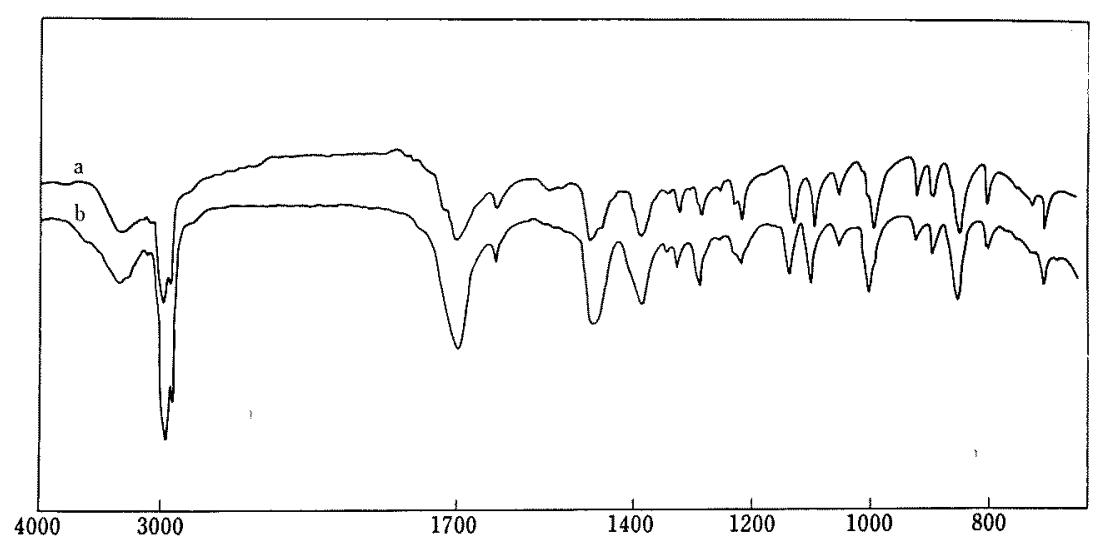

FIG. 1. Infrared Spectra of Natural Phyllostine (a) and Synthetic dl-Phyllostine (b) in Nujol Mull.

$\left(2 \mathrm{H}, \mathrm{S},-\mathrm{CH}_{2} \mathrm{O}-\right), 3.92\left(2 \mathrm{H}\right.$, broad $\left.\mathrm{S}, \mathrm{\lambda}_{\mathrm{H}}\right)$. matography of this product were also identical The other compound (125 mg) was recrystal- with those of the natural. lized from chloroform to give pure $d l$-phyllostine (I), mp $47.5 \sim 48^{\circ} \mathrm{C}$, Anal. Found:C, 54.65; $\mathrm{H}$, 3.95. Calcd. for $\mathrm{C}_{7} \mathrm{H}_{6} \mathrm{O}_{7}: \mathrm{C}, 54.55 ; \mathrm{H}$, $3.92 \%$. The IR (Fig. 1), UV and NMR spectra of the synthetic product (I) were identical with those of the natural product, and the behaviors on TLG and paper chro-

Akitami ICHIHARA Kengo ODA Sadao SaKamura

Depariment of Agricultural Chemistry, Hokkaido University, Sapporo, Japan

Received December 16, 1970 